\title{
Multimodal- Stylistic Representation of Comparison in Airtel Nigeria 4G Visual Commercials
}

\author{
Evangeline Agwa Fomukong Seino \\ English Modern Letters \\ Higher Teacher Training College \\ The University of Bamenda, Cameroon
}

Received: May 19, 2020 Accepted: February 6, 2021 Published: February 12, 2021

doi:10.5296/jsel.v9i1.18295 URL: https://doi.org/10.5296/jsel.v9i1.18295

\begin{abstract}
In semiotics, a code of communication which is a set of conventions used for meaning making can be spoken language, written language or an image. Modes of communication are used to accomplish a desired effect in daily social interaction. This social interaction can be found in the communication between the advertiser and the consumer, and the writer and the reader. This study analyses some of these modes used in the Airtel Nigeria 4G visual commercials and examines how the advertisers make use of the concept of the composition of elements in a multimodal text which bases on the idea that the advertisers and the viewers are abreast with what information is mutually known and understood. This view is explicitly shown in the composition of elements, words and images, combine aesthetics and persuasion through meaningful elements that form a coherent text of code-specific structures that produce meaning. The study follows the survey research design and the data is analysed following four steps of assigning incidents to frames, elaborating frames, relating themes to frames and interpreting the data as a coherent structure. The study concludes that the advertisers of Airtel Nigeria $4 \mathrm{G}$ visual commercials make ample use of metaphors associating $3 \mathrm{G}$ with negative frames and $4 \mathrm{G}$ with positive frames, drawing inspiration from gargets used daily by their audience. They vividly and successfully create a demarcation between $3 \mathrm{G}$ and $4 \mathrm{G}$, persuading consumers to go for the Airtel Nigeria $4 \mathrm{G}$ products.
\end{abstract}

Keywords: multimodal, frame, comparison, polarity, $4 \mathrm{G}$, advertisement 


\section{Introduction}

Communication is effective when the reader and writer, the listener and the speaker, the advertiser and the consumer, the designer and the interpreter all use codes understood by both of them. In communication, codes can be connotational and ideological, reflecting particular events which can be social, political or religious. Semiotics studies the production, transmission and interpretation of meaning represented symbolically in signs and messages, primarily but not exclusively in language. According to Kress and Van Leeuwen (1996, p.48) the semiotic code of language and the semiotic code of pictures each have their own particular means of realising what in the end are perhaps quite similar semantic relations. What in language can be realised by words of the category 'action verbs' is in pictures realised by elements that can be formally defined as vectors. What in language is realised by locative preposition is realised in pictures by formal characteristics that create the contrast between foreground and background. This is not to say that images are exactly as language but they can say some of the same things as language. What in language is realised by means of syntactic configurations of certain classes of nouns and certain classes of verbs is in pictures realised, and made perceivable and communicable by vectorial relations (Kress and Van Leeuwen, 1996). They go on to assert that the question of truth and reality remain insecure, subject to doubt and uncertainty, and even more significantly, to contestation and struggle. Multimodal analysis integrates two or more semiotic modes of communication to make meaning. This means that other semiotic modes especially the visual are put together with linguistic elements. In this situation there is an interconnection between modes. These multimodal elements include linguistic elements made up of the different linguistic levels, audio elements which are made of pitch, rhythm of music and sound effects and visual elements involving moving images and colours (p.181). All these are designed by advertisers in a way that as members of a society, consumers have to be able to make decisions like buying products, on the basis of the information they receive, from the advertisements.

Advertisers send out messages to promote or sell a product, service or idea, targeting a particular audience. Advertising is communicated through various mass media including newspapers, television, radio, outdoor advertising or direct mail, blogs, social media, websites or text messages. The intention of advertisements is often to generate increased consumption of the products or services of companies through branding which associates a product name or image with certain qualities in the minds of consumers. Commercial differentiation comes with comparing one product to another, demonstrating the superiority of the product, showing customers that difference can have a positive effect on the consumer. As Fomukong (2016, p.105) opines, the powerful influence language has on people makes the encoders to be selective in the kind of language and communication they use in advertising. Fomukong uses Jeffries' (2010) Textual Conceptual Functions to analyse the Dangote cement advertisement. Torto $(2016$, p.48) in his analysis of descriptive features in advertisement posits that advertisers use a variety of techniques to grab the attention of the audience, to establish credibility and trust, to stimulate the desire for a product or service and to motivate consumers to act. He analyses the use of sensory details, figurative language, grammatical modifications and picturesque vocabulary in different descriptive texts. Airtel 


\section{Macrothink}

Nigeria in its $4 \mathrm{G}$ commercials focuses on comparison of methods and gargets to showcase its 4G products. In comparison, two things are evaluated by determining the relevant characteristics of each thing to be compared, determining the degree of similarity and difference. In order to compare things they must have characteristics that are similar enough in relevant ways (comparison,n.d). Adjectives and adverbs compare one person or thing with another and enable us to say whether a person or thing has more or less of a particular quality. Comparison, therefore, is the modification of an adjective or adverb to denote different levels of quality, quantity or relation. Airtel Nigeria $4 \mathrm{G}$ advertisers use this as a memorable concept, leaving vivid pictures in the minds of the consumers. They do this by creating themes and frames in the minds of the consumers to depict polarity. The negative and positive polarities are shown through the use of adjectives that portray vivid images and emotionally loaded language that will possibly evoke positive response from the audience. This study examines the multimodality of Airtel Nigeria $4 \mathrm{G}$ visual commercials that use metaphor as a means of persuading the audience to buy its $4 \mathrm{G}$ devices. To carry out this investigation the following questions are answered in the paper: how do the advertisers blend the visual images and text messages in their multimodal advertisements and how is the concept of 'better' expressed in the advertisements? These questions are answered by analysing how advertisers use comparison in images and texts, how the different modes in the advertisements increase the understanding and perception of the viewers and how the advertisers explore the semantic relations between the visual, audio and linguistic resources surrounding the Airtel Nigeria 4G visual commercials.

\section{Background}

Airtel Network limited is a telecommunications service provider in Nigeria with headquarters in Lagos. It ranks amongst the top four mobile service providers in terms of subscribers with a customer base of more than 39.8 million. The company's product offerings include $2 \mathrm{G}, 3 \mathrm{G}$ and $4 \mathrm{G}$ wireless services, mobile commerce and enterprise services. The company's mobile networks cover over $70 \%$ of Nigeria's population and its $3 \mathrm{G}$ coverage is over $41 \%$ (www.airtel.com.ng). 3G, short for third generation, is the third generation wireless mobile telecommunication technology. It is the third type of access technology that has been made widely commercially available for connecting mobile phones. The development of $3 \mathrm{G}$ services in the early years of the $21^{\text {st }}$ century was a major step forward both in terms of reliability for voice calls and text messaging as well as providing far more rapid access to the internet due to its capabilities of carrying large amounts of data (www.lifewire.com). Lifewire (n.d) describes $3 \mathrm{G}$ as fast enough for plenty of uses, having wider spread availability and supported by older devices and may be, more stable. 3G comes with enhancements over previous wireless technologies, like high-speed transmission, advanced multimedia access, and global roam. $3 \mathrm{G}$ provides enhancements over $2 \mathrm{G}$ in that it has several times higher data speed and the transfer rate for $3 \mathrm{G}$ networks. While $3 \mathrm{G}$ is still widely used, it is no longer the fastest and newest method of carrying mobile data as it has been superseded by 4G. Lifewire (n.d) considers $4 \mathrm{G}$ to be considerably faster, better for data-intensive tasks, like streaming video, having a wider range and possessing improved security. $4 \mathrm{G}$ is therefore faster than $3 \mathrm{G}$. 
Since technology is moving fast, everyone likes to use fast connections.

\section{Conceptual Framework}

This study uses a conceptual basis of composition in a multimodal text which includes: information value, salience and framing.

\subsection{Composition of Elements in a Multimodal Text}

As stated by Kress and Van Leeuwen (1996, p.181), any given image contains a number of representational and interactive meaning making relations. This is seen through three interrelated systems in the composition of elements in a multimodal text which are information value, salience and framing.

\subsubsection{Information Value}

Information value gives the idea on the layout of information in an advertisement. The pages on the right usually have the key information of what the reader must pay attention to. It follows that the left is the side of the already given, something the reader is assumed to know already, as part of the culture. The elements placed on the left are Given while those placed on the right are New. New, means that it is something which the viewer must pay special attention to. Left and right, can also be presented as before and after (Kress and Van Leeuwen 1996, p.188). Anderson et al.(2003)) define Given and New information as a distinction between information that is assumed or supplied by the speaker and that which is presented for the first time. The Given information is inferable by the addressee at the time of the speaker's utterance, because it is knowledge shared by both the listener and the speaker, part of the extra linguistic context, and previously established in the discourse and is placed earlier in the sentence. For something to be Given means that it is presented as something the viewer already knows as a familiar and agreed-upon point of departure for the message. And for something to be New means that it is presented as something which is not yet known, or perhaps not yet agreed upon by the viewer, hence as something to which the viewer must pay special attention. In writing, New is presented later in the sentence, it is stressed and expressed in more elaborate fashion. It is therefore problematic and contestable while Given is presented as self-evident. The logic behind the Given and the New is that the earlier sentences make later ones more intelligible. Nordquist (2020) states the linguistic principle that speakers and writers tend to express known information (the Given) before unknown information (the New) in their messages. In the Given and New, the composition is polarized. This study provides inventories of the major compositional structures which have become established as conventions from the semiotic perspective, and analyses how they are used to produce meaning by contemporary image-makers. From the Airtel Nigeria 4G visual commercials, the Given which is the shared information is about the traditional methods and old things, representing $3 \mathrm{G}$ and presented before the New, 4G, which are modern methods and equipment.

\subsubsection{Salience}


Kress \& Van Leeuwen (1996, p.225) agree that salience is the degree to which an element draws attention to itself, due to its size, its place in the foregrounding or its overlapping of the other elements, in its colour, its tonal values, definition and other features. Salience can create a hierarchy of importance among the elements selecting some as more important, and more worthy of attention than others. In this paper, salience focuses on the selecting of frames that are more important. The colour and tonal values are not considered.

\subsubsection{Framing}

Framing is the way pieces of information are organised and the way concepts are presented to give the desired effect (Itamar, 2016). In framing, elements or groups of elements are disconnected, marked off from each other or connected, joined together (Kress and Van Leeuwen 1996, p.214). In visual framing it is a matter of degree. Elements of the composition may be strongly or weakly framed. The stronger the framing of an element, the more it is presented as a separate unit of information. Disconnection in framing is the degree to which an element is visually separated from other elements through framelines, pictorial framing devices, empty space between elements, discontinuities of colour and shape, and other features. Connection in framing is the degree to which an element is visually joined to another element, through the absence of framing devices, through vectors, and through continuities of similarities of colour and visual shape (p. 225). In framing theory, the media focuses on certain events and places them within the field of meaning. It suggests that how something is presented to the audience influences the choices people make about how to process that information. The frames help to organise meanings, enhance understanding, influence data interpretation and communication. Some aspects are selected and presented to draw attention. In this case, the advertiser might present the frame in a negative or positive manner. The positive frame emphasizes benefits of purchasing the product while the negative frame presents the disadvantages of may be the other products.

In advertisement framing is important because the manner in which messages are presented has an effect on the purchases made by consumers. Advertisers use frames powerfully to influence how consumers will interpret and comprehend the message on the advertisement. This study looks at framing from both the disconnected and connected point of view since comparison is examining the similarities and dissimilarities. For two things to be compared they must first have a connection. The Airtel Nigeria $4 \mathrm{G}$ visual commercials compare the degree to which one object performs better than the other. The traditional and modern methods both do the job but it is better to have the modern methods which evolve with life. The fact that the gargets Airtel Nigeria 4G visual commercials present both do the job, make them connected and similar. The disconnection is seen in the dissimilarities using polar frames to show the degree in performance.

\section{Methodology}

The survey research design is used in the collection and analysis of data. The data was collected mostly on the Airtel Nigeria web pages, YouTube channels and Facebook accounts. 


\section{Macrothink}

Journal for the Study of English Linguistics

ISSN 2329-7034

2021, Vol. 9, No. 1

The data comprise six Airtel Nigeria 4G visual commercials: 4G-Portmanteau, 4G-Blender, 4G-Gele, 4G Device, the Multipurpose Chopper and the Lantern. Most of the advertisements were first seen over the Nigerian TV channel 'AMShowcase' and the image collected online from Airtel web pages. The portmanteau, Blender, Gele and 4G Devices are videos while the Multipurpose Chopper and the Lantern are static advertisements. The data for analysis used is the framing of elements in images and language used in the commercials. A descriptive approach is used in reporting the findings. This study adapts a technique for identifying frames for qualitative research analysis from Winner and Dominick (2006). Winner and Dominick (2006, pp. 117-118) elaborate on four steps of analysis which include: comparative assignment of incidents to categories (or frames), elaboration of refinement of categories/frames, searching for relationships and themes among categories/frames and simplifying and integrating data into a coherent theoretical structure. Even though the above technique is used for identifying news frames, it is suitable for analysing moving and static advertising frames.

\section{Results and Discussion}

This section discusses the description of the different metaphors used in explaining the superiority of the Airtel $4 \mathrm{G}$ devices, which include the visual and the verbal advertisements. It also discusses the themes highlighted and the degree of framing.

\subsection{Description of the Commercials}

The different commercials that are described in this section are 4G-Portmanteau, 4G-Gele, 4G-Blender (the grinding stone, the beat-down 'ijabe', the mortar/pestle), Airtel 4G device (electric mixer), the multipurpose chopper and the lantern .The multipurpose chopper and the lantern are static while the rest are moving images.

\subsubsection{G-Portmanteau}

In the 4G-Portmanteau commercial, the portmanteau is compared to the four-wheeled suitcase. A portmanteau is a large travelling bag, typically made of stuff leather and opening into two parts. The four-wheeled suitcase is a very easy-to-manage travelling bag. The four-wheeled is balanced and easy to use because it can be turned sideways and fit in the aisle in a train, plane or on the floor. In the Airtel Nigeria 4G-Portmanteau commercial, the family has to travel and the traditional mother/ mother-in-law packs her things in a portmanteau. She is actually seen dusting the contents in her travelling case portraying the box as old, meanwhile her daughter-in-law who has a four-wheeled suitcase is shown sitting in the car and playing with the child in a very relaxed mood. Her son indicates to her that they are late, and carries the portmanteau with difficulties to the car. It is so difficult to put the portmanteau in the boot, so it is put on the carriage. At the airport, while others are pulling their luggage Mama's son carries hers on his head. He finally falls with the portmanteau exposing everything in it. There, she sees others pulling their four-wheeled travelling bags with ease, rolling them through and immediately goes for hers. At the end, everyone is pulling their four-wheeled suitcases with ease, satisfaction and happiness. The excerpts can be seen in 


\section{Macrothink}

figure1.The four-wheeled requires less effort to wheel and each wheel can turn 360 degrees to change direction. Even when packed to capacity they are easy to pull along. The commercial shows luggage as a crucial part of ones travel so every traveller needs a traveller's bag that is sturdy, reliable and that will last through many flights, train rides and transfers through pavement (https://www.adsoftheworld.com).
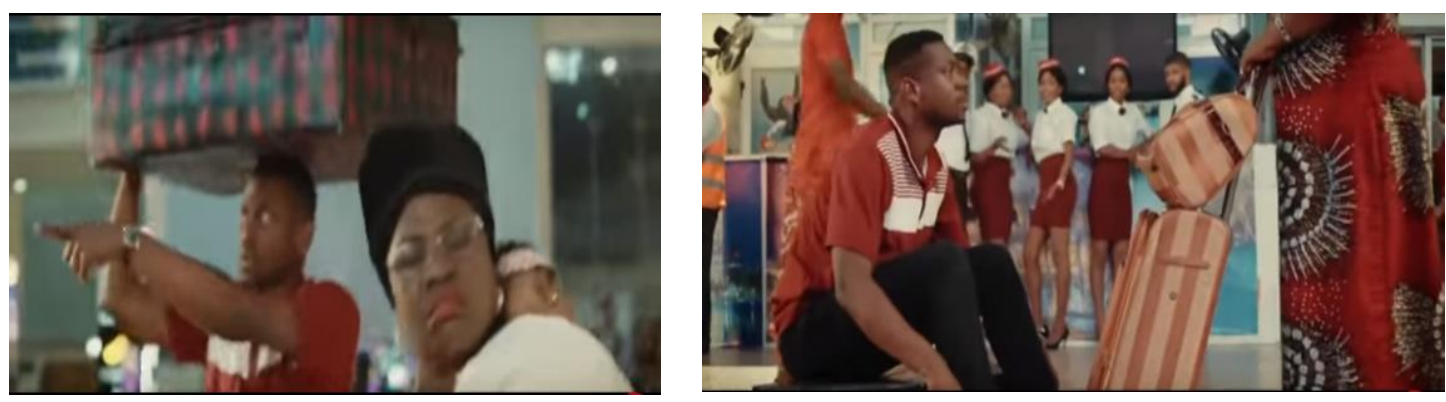

Figure 1 The portmanteau and the four-wheeled suitcase

Source: https://www.adsoftheworld.com

The above picture compares the difficulty in carrying the portmanteau (left) with the ease in handling the four-wheeled travelling bag (right).The verbal commercial reads:

$3 \mathrm{G}$ is Great $4 \mathrm{G}$ is Better

You don't know what you're missing till you experience it.

Buy an Airtel sim to enjoy double data on Nigeria's widest 4G network (https://www.adsoftheworld.com).

Airtel Nigeria 4G advertisers describe this advertisement on YouTube as a TV spot that uses a metaphor of travelling boxes to show the superiority of its 4G network. 'Mama sure didn't know what she was missing until she experienced it. Upgrade to 4G.' (https://www.adsoftheworld.com). Using the metaphor of the travelling bags, the advertisers call on viewers to experience the Airtel 4G, just as Mama experiences the four-wheeled suitcase and derives satisfaction because of the ease in handling the suitcase. The portmanteau represents $3 \mathrm{G}$ while the four-wheeled suitcase represents $4 \mathrm{G}$.

\subsubsection{G Gele}

Gele is a tall elegant head piece worn by women from Nigeria. Though originally worn by women from the Yoruba tribe it has become a popular fashion accessory for all women across the country, usually used for a social function. On special occasions, it is worn over an 'iro' (a wrap-around skirt) and 'buba' (a loose fitting blouse). The gele is usually made out of heavy or stiff fabric that can be wrapped and moulded into a specific shape (worldbride.wordpress.com). The gele is used now in many parts of Africa and is very important to women's fashion. This may vary according to the culture of the people. Though the gele is common place for women in the Nigerian culture, women can have both the casual and sophisticated gele. Women wear it to weddings, birthday and chieftaincy parties. 


\section{$\triangle 1$ Macrothink}

4G-Gele commercial portrays comparison through the metaphor of the head piece that is tied and the gele that is worn. The event is the celebration of the $76^{\text {th }}$ anniversary of Mama. Her daughter-in-law is seen wearing her gele with ease but Mama is struggling to get hers done and is taking so much time on it. In that struggling and difficulty she manifests anger and dissatisfaction. At the party everyone is worried because she is not yet there. She finally succeeds to tie it with the help of her friends who come to celebrate with her. She gets into the hall with excitement after her audience has waited for her for a long time. She dances, bowing and while lifting up her head the head piece gives way. The audience expresses disappointment and the women hurriedly shield her from the embarrassment and take her into a dressing room where they present a gele (what they are putting on) to her. In a few seconds she is back on stage with the gele and everyone is excited. She dances again, bowing and lifting her head, the very dance style. Everyone is worried that it might fall off but this time because it is the gele, it remains firm on her head and the audience shouts for joy. The celebrant is also happy and very satisfied. The $4 \mathrm{G}-\mathrm{Gele}$ commercial is about the Nigerian culture of celebrating and guaranteeing ones clothing which is a priority, and places one to be superior to others like $4 \mathrm{G}$ is superior to $3 \mathrm{G}$. The gele is more like a cap that just fits. It is designed as a cap to be worn, so very little effort is needed in putting it on. At first, when she is tying the head piece she is angry because the process to get the desired design is difficult. For her to tie the head piece, two other women have to come and help her but it still gives way when she is dancing.
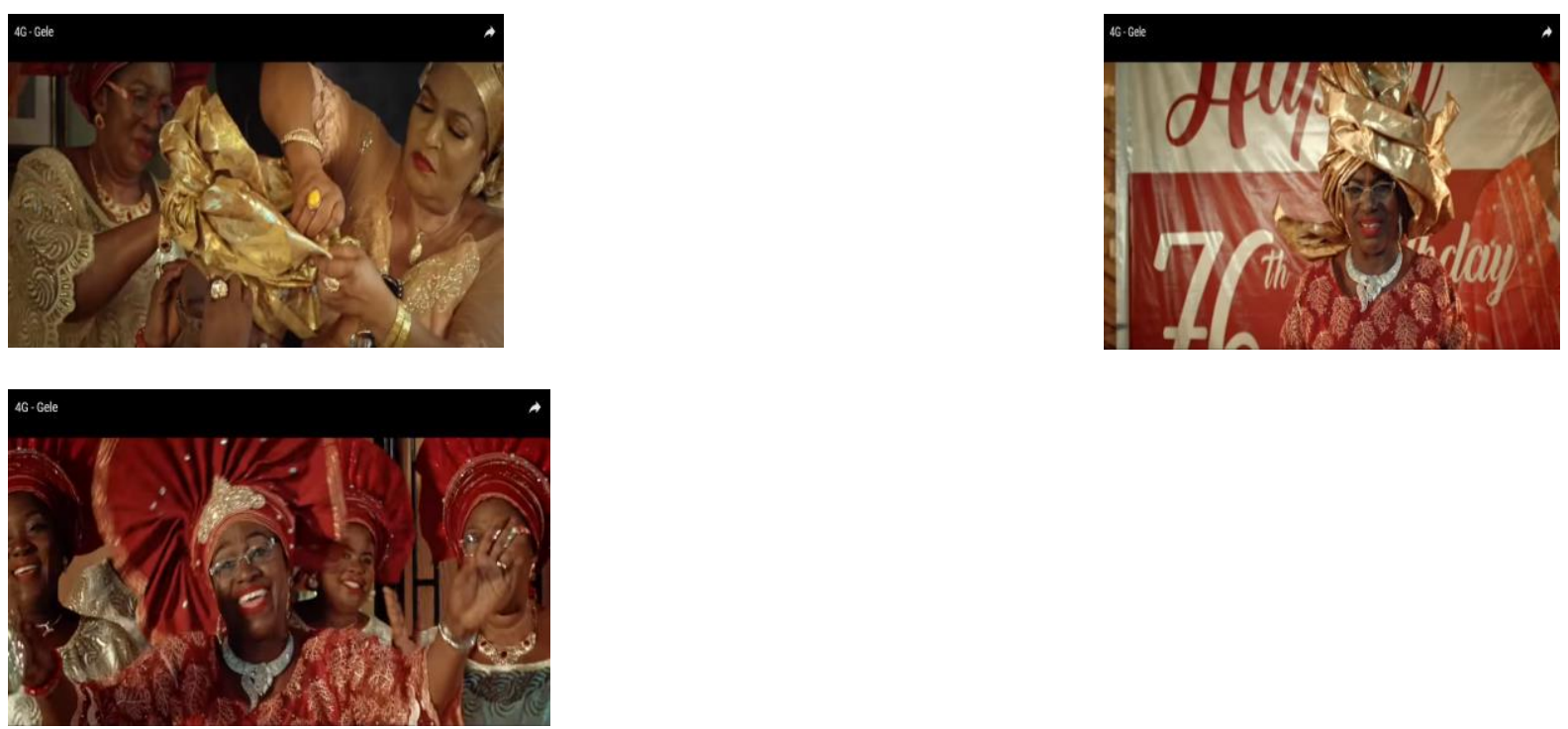

Figure 2 Some of the highlights in the advertisement moving from the head piece to the gele

Source: https://www.adsoftheworld.com

Figure 2 portrays pictures of the head piece and the gele. The first picture from the left shows the stress in tying the head piece. The second from the left portrays the head piece that is scattered at the party and the last from the left presents the gele and its stability on the celebrant's head. The second picture shows frustration while the last shows excitement and happiness. The Given which is the head piece that both the advertisers and the consumers 
already know comes before, on the left while the New, the gele, comes at the end, on the right. The text reads:

$3 \mathrm{G}$ is Great $4 \mathrm{G}$ is Better

You don't know what you are missing till you experience it. Upgrade to a 4G device.

The YouTube advertisement reads: 'A lot of things can get better, even tying gele. You really never know what you are missing till you experience it. Upgrade to a $4 \mathrm{G}$ device and SIM to enjoy data on Nigeria's widest 4G Network \#3GIsGreater4GIsBetter'(https://www.adsoftheworld.com). According to Airtel advertisers in 4G-Gele, the metaphor of the traditional head piece worn by Nigerian women is to show how old ways of doing things are gradually evolving, while also hinting at the superiority of its $4 \mathrm{G}$ network over 3G ( https://www.adsoftheworld.com) .

\subsubsection{G-Blender}

A blender is an electrical mixing machine, used in the kitchen and laboratory in blending food into a liquid, a puree or chopped substances. It is used by the Airtel $4 \mathrm{G}$ advertisers as a metaphor of kitchen rivalry to pass across their message of 'better'. The blender stands superior to the grind (grinding stone), the beat-down (ijabe) and the mortar/pestle. These Airtel Nigeria 4G visual commercials compare the grinding stone, 'ijabe' and the mortar/pestle with the blender. The commercials carry two women, one using the traditional methods of crushing and the other using the modern method.

\subsubsection{The Grinding Stone}

The grinding stone is fashioned from stones or hard rocks and it is used especially to grind many different African spices. To use the grinding stone, one has to kneel and /or bend forward, holding the upper millstone which is smaller, with both hands and work it forward and backwards, grinding the food item placed on the large stone. Shoemaker \& Davies (2019) give archaeological information in Eastern Africa on the grinding stone tool(as shown in the first picture from the left in figure 3). They describe the hand stones as having one or more working surfaces characterised by flattened facets with evidence of crushing and polishing. They argue that though frequently cited use for grinding stone tools in Africa is plant processing, both the ethnographic and archaeological records lend support for there having been numerous processing tasks performed with various grinding- stone tools for different functional and social applications. African communities continued inventing tools often made with what was available where they lived. Some of the tools, specifically stone tools, have existed for centuries, and even after the interaction with Europeans, some communities have continued to use them. The grinding stone is very important in the African homestead, and the woman knees behind it to grind grains, leaves and pepper. The advertisement begins with the traditional woman crushing pepper on the grinding stone and the other using the blender. The one with the stone is tired and looks at the other angrily. She exerts much force to grind. The woman with the blender is relaxed and just presses a button for the blender to crush. In 


\section{Macrothink}

Journal for the Study of English Linguistics

ISSN 2329-7034 2021, Vol. 9, No. 1

addition to the use of much energy and strain, it is disadvantageous in using the stone in that if the pepper touches the grinder's hand it leaves a burning sensation.
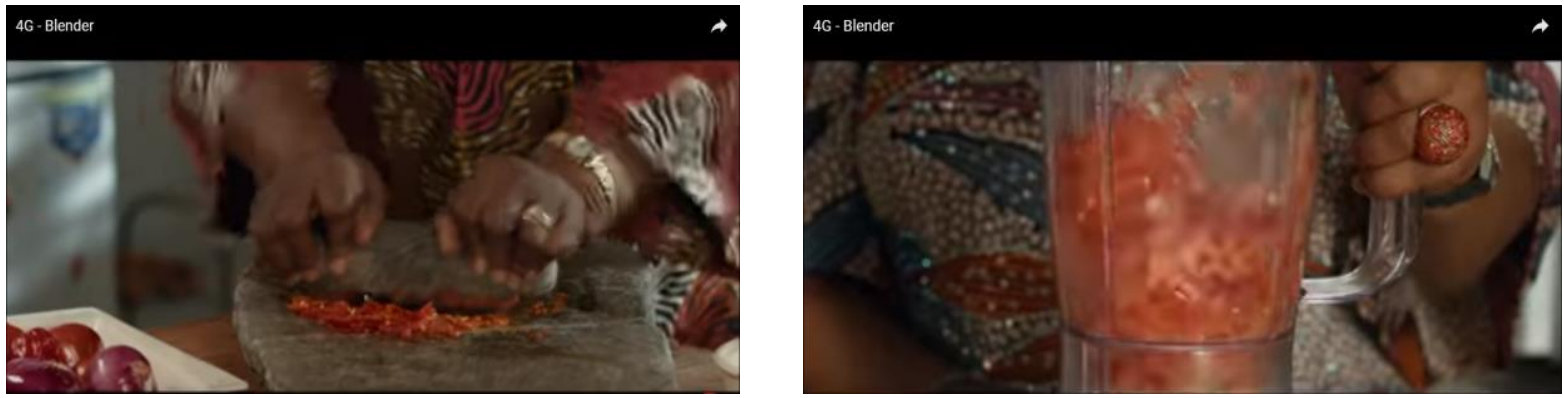

Figure 3 The grinding stone and the blender

Source: https://www.adsoftheworld.com

Figure 3 presents two pictures. First from the left, the woman is using the grinding stone which represents $3 \mathrm{G}$. Her fingers are shown to be holding the upper stone tightly and it shows that much energy is being exerted to grind. The second picture portrays the pepper in the blender.

\subsubsection{The Beat-down 'ijabe'}

The 'ijabe' is a small bunch of broomsticks used to mash mellow leaves (jute leaves) to prepare a slimy soup called 'ewudu' in Nigeria. The bunch of broomsticks is used to chop the leaves manually. The broom has an even tail, is firm binding and easy to grip but very difficult to chop the leaves. The commercial carries the comparison between the 'ijabe' and the blender. The traditional method is used by the very woman using the stone. The woman using the ijabe again uses force and is angry, while the one using the blender is relaxed.
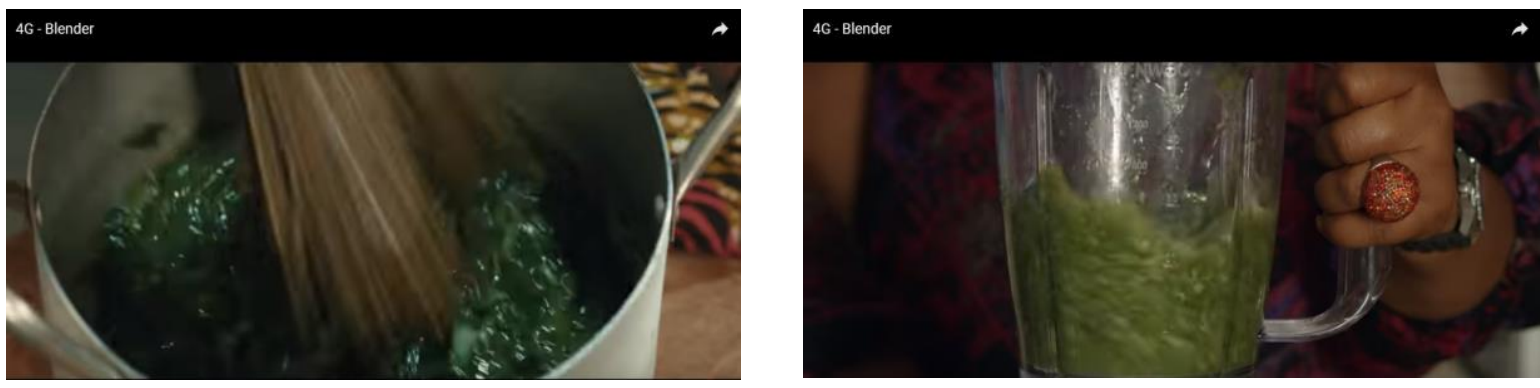

Figure 4 The ijabe and the blender

Source: https://www.adsoftheworld.com

Figure 4 shows the 'ijabe' being used to beat mellow leaves in the first picture from the left and the last picture shows the mellow leaves in the blender.

\subsubsection{The Mortar / Pestle}

A mortar is a bowl shaped container made of hard wood, marble, pottery or stone. The pestle is a bat shaped tool used for pounding inside the mortar. Both are made of the same material. 


\section{Macrothink}

Journal for the Study of English Linguistics

ISSN 2329-7034 2021, Vol. 9, No. 1

In Nigeria the mortar / pestle is usually made of hard wood and is another popular tool used to mill and pound food like crayfish, okra, and cocoyam. The comparison here is between the mortar / pestle and the blender. The traditional woman is using the mortar to crush the crayfish while the other woman is using the blender. The commercial ends with the woman using the traditional tool, trying to use the blender to grind vegetables in the absence of the woman who first uses it. She does not know how to use it, so she puts the vegetable in the wrong cup and grinds with it open. It scatters in the kitchen. Leaving the mortar / pestle for the blender portrays the positive qualities of the blender and in reality, it insinuates moving from $3 \mathrm{G}$ to $4 \mathrm{G}$.
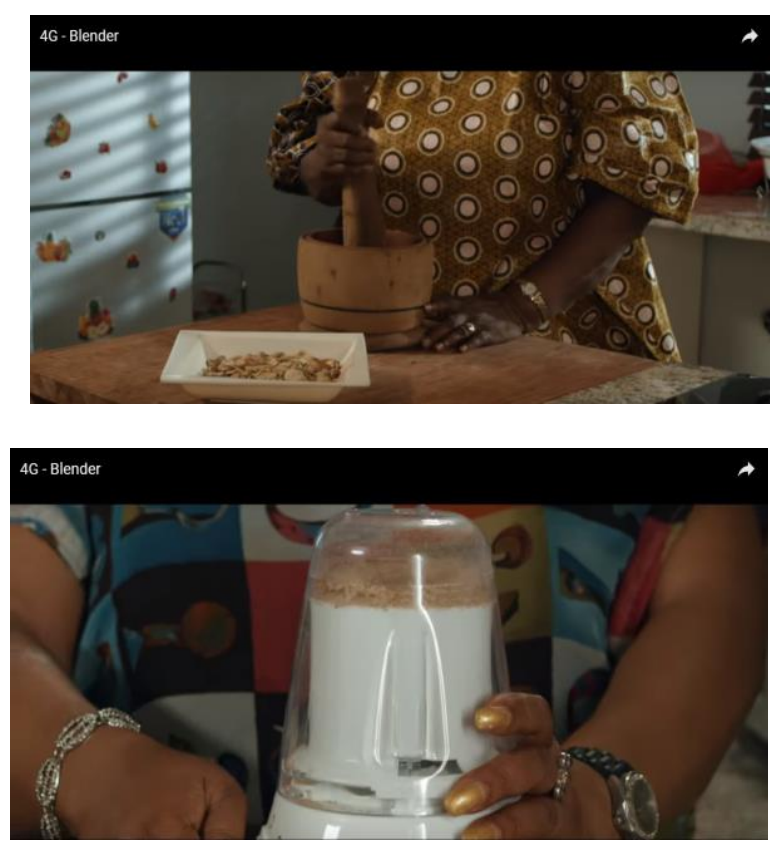

Figure 5 The mortar/pestle and the blender

Source: https://www.adsoftheworld.com

The comparison in figure 5 is between the mortar/ pestle and the blender. From the commercial, the lady using the mortar/pestle is stressed up and uses so much energy. The next picture on the right portrays the blender used to crush crayfish. After the moving images the text reads:

Life evolves, You should too

$3 \mathrm{G}$ is Great $4 \mathrm{G}$ is Better

Buy an Airtel sim to enjoy double data on Nigeria's widest 4G network(https://www.adsoftheworld.com).

The 3G in this commercial is represented by the grind, the beat down and the mortar / pestle and $4 \mathrm{G}$ is represented by the blender. To move from using the $3 \mathrm{G}$ to $4 \mathrm{G}$ is an evolution. The 4G-Blender commercial as described on YouTube is a spot that features two consistent 


\section{Ml Macrothink}

Journal for the Study of English Linguistics

ISSN 2329-7034

2021, Vol. 9, No. 1

characters from the world of Airtel, and shows that while there is nothing wrong with traditional food preparation methods, adopting newer ways would not hurt either.' (https://www.adsoftheworld.com). This is a metaphor that hints at the superiority of its $4 \mathrm{G}$ network (https://www.adsoftheworld.com).

\subsubsection{Airtel 4G Device}

The Airtel 4G Device commercial presents how two women in the kitchen mix dough. The first woman uses the tradition method that is, using her fingers to mix while the second woman uses the modern method which is the electric mixer. Mixing with the fingers is more difficult because at the end the mixture is not smooth, thereby causing the woman to be dissatisfied. The woman mixing with the electric mixer is smiling because she mixes with ease and her mixture is smooth. The advertiser considers the $4 \mathrm{G}$ device offered by Airtel to be 'affordable and it gives you access to the better side, what more can you ask for' (https://www.youtube.com).
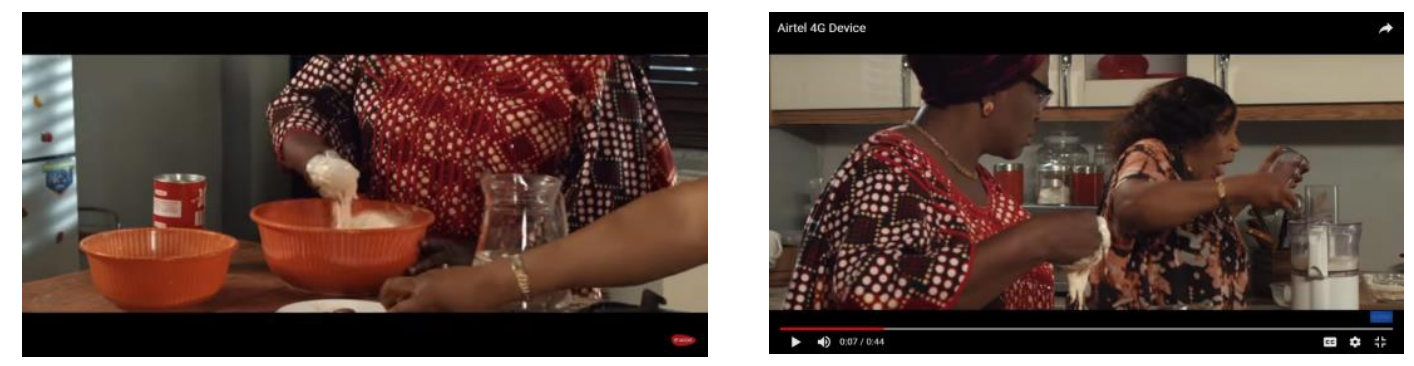

Figure 6 Using the hand to mix and using the electric mixer

Source: Airtel Nigeria: https://www.youtube.com.

In the first picture in figure 6 the woman uses her fingers to mix while in the second picture from the left the other woman uses an electric mixer. The verbal message (https://www.youtube.com) reads thus:

Life Evolves, You should too

Upgrade to a $4 \mathrm{G}$ device

According to the advertisers, evolving like life makes things to be done easily and quickly. Metaphorically, the woman mixing with her fingers has to upgrade to mixing with the electric mixer, insinuating that those with $3 \mathrm{G}$ have to evolve to $4 \mathrm{G}$ to enjoy a better life.

\subsubsection{Airtel Nigeria (The Multipurpose Chopper/Cutter)}

The Airtel 4G commercial uses the kitchen once more to show the superiority of the Airtel 4G device. The advertisement compares the chopping board to the multipurpose chopper and the example used is to chop onion. In the commercial there is a knife close to the onion on the chopping board indicative of the fact that one has to use the knife to chop the onion. The advertiser shows the multipurpose chopper and the onion placed on the blades. What one has to do is to press on the cover which will press the onion on the blades and immediately, the onion will be chopped. The multipurpose chopper is a kitchen garget that is easier to use and 


\section{NI Macrothink}

makes cooking faster and less stressful. The chopping board represents the $3 \mathrm{G}$ while the multipurpose chopper represents the 4G Airtel.

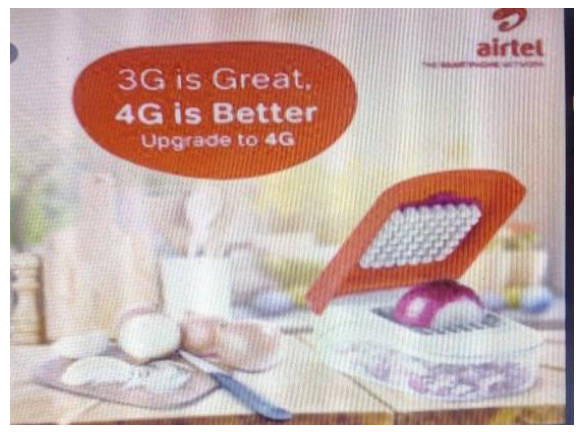

Figure 7 The Chopping Board and the Multipurpose Chopper

Source : Airtel Nigeria https://www.facebook.com

Figure 7 is a static picture which presents the chopping board on the left and the multipurpose chopper on the right.The advertisement reads: 'Enjoy a better and sweet browsing experience with Airtel 4G'(https://www.facebook.com). The multipurpose chopper is encouraging consumers to buy the Airtel $4 \mathrm{G}$ products which have high speed in browsing.

\subsubsection{The Lantern and the Recharge Lamp}

Another comparison between $3 \mathrm{G}$ and $4 \mathrm{G}$ is done through the lantern and the recharge lamp. The lantern commonly known as 'bush lamp' is what is used where there is no electricity or when there is electricity shortage. It is portable, reliable for outdoors and uses a wick that lights at the top and connects into a tank that contains kerosene. The light at the tip is protected by a globe that encloses the wick. The lantern emits smoke that causes sooth making the lamp dirty and can affect the eyes. It is fragile and needs regular cleaning. The recharge lamp on the other hand, needs just solar energy for charging and shines brighter than the lantern. The recharge lamp is replacing the lantern kerosene lamps because it is brighter, cleaner, easier to handle and cheaper to maintain. The comparison between the lantern $(3 \mathrm{G})$ and the recharge lamp (4G) is convincing enough for the consumers to go for the Airtel $4 \mathrm{G}$ products. The advertising message reads '\#3GIsGreat4GIsBetter'.

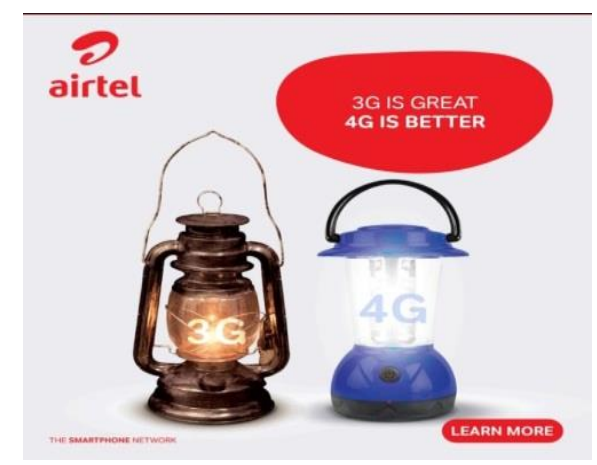

Figure 8 The Lantern and the Recharge Lamps

Source : Airtel Nigeria https://www.facebook.com 


\section{Ml Macrothink}

Figure 8 portrays the lantern on the left which represents $3 \mathrm{G}$ and a recharge lamp on the right which represents $4 \mathrm{G}$. The text by the image reads:

Life Evolves, You Should Too

Upgrade to an Airtel $4 \mathrm{G}$ sim and get $3 \mathrm{G}$ for $1 \mathrm{~km}$ on the network with the widest $4 \mathrm{G}$ coverage. $3 \mathrm{G}$ is Great $4 \mathrm{G}$ is Better.

Eating dinner around this lantern supported by the moonlight was feast mode but when rechargeable lamps came into our lives, WE SAW THE LIGHT (Airtel Nigeria https://www.facebook.com).

The advertiser proposes $4 \mathrm{G}$ by saying that even though the moon had to support the lantern it was still not as bright because when the recharge lamps came, its light was brighter.

\subsection{Themes and Frames}

The themes connect the different gargets used in the commercials. The gargets perform the same functions, for example, the portmanteau and the four-wheeled suitcase, both perform the same job but the difference comes in the frames which show the degree to which the gargets perform the functions.

Table 1 Themes and frames highlighted in the Airtel 4G visual commercials

\begin{tabular}{|l|l|l|l|}
\hline S/N & THEMES & $\begin{array}{l}\text { FRAMES } \\
\text { Negative polarity }\end{array}$ & $\begin{array}{l}\text { PRAMES } \\
\text { Positive Polarity }\end{array}$ \\
\hline 1 & Method & Traditional & Modern \\
\hline 2 & Manageability & Difficult & Easy \\
\hline 3 & Garget & old & New \\
\hline 4 & Countenance & Angry & Happy \\
\hline 5 & Mood & Tense & Relax \\
\hline 6 & Fulfilment & Dissatisfied & Satisfied \\
\hline 7 & Time & Slow & Fast \\
\hline 8 & Energy & More Energy & Less Energy \\
\hline 9 & Certainty & Apprehensive & Confident \\
\hline
\end{tabular}

As seen on Table 1, the interpretation of the moving images might be subjective to an extent but it gives a vivid picture of the intention passed across by the advertisers. The themes and frames developed on the table are what can be found on the commercials. The advertisers create, develop and highlight themes and frames they want to use in convincing the viewers to buy their products. The positive frames are highlighted against the negative frames. The 
difference is portrayed by laying emphasis on how easy, fast and satisfactory life can be with modernity, which in the commercials are metaphors of $4 \mathrm{G}$.

The commercials follow the concept of information structure which explains the reason for the choices the advertisers make on how to phrase their utterances related to Given and New. The ideology here is moving to the upgraded version of something. The old or Given information, that which comes before and is portrayed on the left carries negative frames to emphasize. The New information which comes after the old is placed on the right and carries positive frames. The ideology is expressed through the concept of 'better' which portrays a new product to be of a greater degree and more appropriate than the old one. Comparing these pairs of gargets using themes and frames, that portray the difference between $3 \mathrm{G}$ and $4 \mathrm{G}$, stresses on the advantage of going for the $4 \mathrm{G}$ product. This makes the viewers to look at life from a differentiated point of view. The belief in society creates a state of inequality making those using the $4 \mathrm{G}$ products to be of a higher class. The Airtel Nigeria $4 \mathrm{G}$ visual commercials create a value which directs the attitudes towards buying a product, through determining what is important. These values are presented through the creation of themes which are broken to frames that have positive and negative values. The advertisers call on viewers to upgrade to $4 \mathrm{G}$ which is better; they call on viewers to experience $4 \mathrm{G}$ to know what they are missing and evolve like life. In this study the various codes are analysed together treating the meaning as parts interacting with and affecting one another. The images are metaphors and the texts are straight forward in linking the metaphor to the $4 \mathrm{G}$ which is what is actually being advertised. The frames show that both instruments (the old and the new) get the work done but one is better than the other. The frames further insinuate that the Airtel 4G device is more comfortable, faster, easier to handle, modern, and used without stress. Upgrading from portmanteau, head piece, the grind/the beat/the mortar/pestle, hand mix, chopping board and lantern to the four-wheeled suitcase, gele, blender, electric mixer and recharge lamp respectively is upgrading from $3 \mathrm{G}$ to $4 \mathrm{G}$.

\section{Conclusion}

In the Airtel 4G advertisements, Given and New can be easily determined by the position, following information packaging in both the visual and the sentence levels. The Given information serves as a link of relevance to the New information, because viewers and advertisers have a common ground. The images show the difference through frames, and the textual message elaborates on moving from the Given to the New, metaphorically moving from the traditional to modern methods and in the real Airtel context, moving from $3 \mathrm{G}$ to $4 \mathrm{G}$. The use of the metaphors of four-wheeled suitcase, gele, blender, electric mixer, multipurpose chopper and the recharge lamp associate the Airtel $4 \mathrm{G}$ product with an image in possession of certain positive qualities in the minds consumers. The blending of the images and texts in the Airtel 4G visual commercials taking into consideration: information value, salience and frames, produce meaning, leading to the understanding and interpretation of the texts by viewers. The study identifies the events, assigns and elaborates on the frames highlighted, identifies the themes and finally integrates the data in a coherent structure, bringing to view 
the consistency and choice of pattern Airtel Nigeria 4G advertisers use as a strategy to persuade their viewers to buy their products.

\section{References}

Airtel (n.d.). Prepaid/Postpaid/4G. Retrieved from https://www.airtel.com.ng

Airtel Nigeria: Retrieved from https://www.facebook.com

Airtel Nigeria: Retrieved from https://www.youtube.com

Airtel Nigeria: Retrieved from https://www.adsoftheworld.com

Alozie, E. (2005). Sudan and South Africa: A Framing Analysis of Mail \& Guardian Online's Coverage of Darfur. Ecquid Novi, 26(1), 63-84.

Anderson, S., Day,D., Jordan,P.C., Loos, E., Wingate,J.D. (Eds.) (2003). Glossary of Linguistic Terms. Dallas: SIL International Digital/Resourses.

Bi, M. (2019). Multimodal Discourse Analysis of News Pictures. Theoary and Practice in Language Studies, 8(9), 1035-1039. http://dx.doi.org/10.17507/tpls.0908.23

Crystal, D. (1985). A Dictionary of Linguistics and Phonetics. New York: Basil Blackwell.

Crystal, D. (1997). Making Sense of English Usage. Edinburge: Chamber.

Fomukong, S.E.A. (2016). Stylistic Analysis in Advertising Discourse: A Case of the Dangote Cement Advertisement in Bamenda-Cameroon. Advances in Language and Literary Studies, 7(6), 105-112. http://dx.doi.org/10.7575/aiac.alls.v.7n.6p.105

Halliday, M.A.K. \& Christian M.I.M. (2013). Halliday's Introduction to Functional Grammar. ( $4^{\text {th }}$ edition). London : Routledge.

Itamar, K. B. (2016). This is How the Framing Effect Can Help Your Conversion Rate. Retrieve from https://www.pagewiz.com

Junge, B., Theakston, A. 1. \& Lieven, E.V.M. (2015). Given-new/ New-given? Children's Sensitivity to the Ordering of Information in Complex Sentences. Applied Pscholinguistics, 36(3), 589-612. http://dx.doi.org/10.1007/S1042716413000350

Ke, Q. \& Wang,W. (2013). The Adjective Frequency in Advertising English slogans. Theory and Practice in Language Studies, 2(3), 275-284. http://dx.doi.org/10.4304tpls.32.275-284

Kress, G. \& Leeuwen T, V. (2003). Reading Images: The Grammar of Visual Design. London: Routledge.

Levinson, S. C. (1983). Pragmatics. England: Cambridge University.

Lifewire, (n.d). Networking \& Security.3G vs 4G:Which is Better? Retrieved from http://www.lifewire.com 


\section{Mll Macrothink}

Journal for the Study of English Linguistics

ISSN 2329-7034

2021, Vol. 9, No. 1

Nordquist, R. (February 12, 2020). Given-Before-New Principle (Linguistics). Glossary of Grammatical and Rhetorical Terms. Retrieved from https://www.thought.com

Norgaard, N. (2008). Multimodal Stylistics of the Novel: More than Words. London: Routledge. http://doi.org/10.1177/0963947008095961

Norgaard, N (2014). Multimodal Stylistics. The Routledge Handbook of Stylistics. http://dx.doi.org/10.4324/9781315795331.ch29

Oluwu, A. \& Akinkurolere, S. O. (2015). A Multimodal Discourse Analysis of Selected Advertisement of Malaria Drugs. English Review: Journal of English Education, 3(2), 166-173.

Pan, Z. \& Kosicki, G. M. (1993). Framing Analysis: An Approach to News Discourse. Political Communication, 10(1), 55-75. http://dx.doi.org/10.1080/10584609.1993.9962963

Pariasamy, M. S., Gruba, P. \& Subramanian, G. (2015). A Multimodal Literary Analysis of a Television Commercial. The Southeast Asian Journal of English Language Studies. 21(3), 151-164.

Shoemaker, A. \& Davies, M.I.J. (2019). Grinding Stone Implements in the Eastern African Pastoral Neolithic. Azania: Archaeological Research in Africa, 54(2), 203-220. https://doi.org/10.1080/0067270X.2019.1619284

Torto, R. T. (2016). An analysis of Descriptive Features in the English Used in an Advertising Text. International Journal of Linguistics and Communication, 4(2), 47-55. http://dx.doi.org/10.15640/ijlc.v4n2a4

Virtamen, T. (1992). Given and New information in Adverbials:Clause-initial Adverbials of time And place. Journal of Pragmatics, 17(2), 99-115. https://doi.org/10.1016/03782166(92)90036-B

Wikipedia Contributors (February 2020). Comparison. In Wikipedia, The Free Encyclopedia. Retrieve at 10pm March 2020, from https://en.wikipedia.

Wimmer, R. D. \& Dominick, J. R. (2006). Mass Media Research: An Introduction ( $8^{\text {th }}$ edition). Canada: Thomson Wadsworth.

World Bride Magazine (2014). The Gele-Nigerian Headwrap-Fashion Piece with History. Retrieve on the 2 of April 2020 from https://worldbride.wordpress.com.

Zhao, X. (2005). Advertising Slogan: Linguistic Features. Dalian: Dongbei University of Finance and Economics. 


\section{Copyright Disclaimer}

Copyright for this article is retained by the author(s), with first publication rights granted to the journal.

This is an open-access article distributed under the terms and conditions of the Creative Commons Attribution license (http://creativecommons.org/licenses/by/3.0/). 